\title{
Comunicación
}

\section{El síndrome de la ecdisis incompleta en machos adultos de Cryphiops caementarius (Crustacea: Palaemonidae) y sus consecuencias en cultivo intensivo}

\author{
INCOMPLETE ECDYSIS SYNDROME IN ADULT MALES OF Cryphiops caementarius \\ (Crustacea: Palaemonidae) and its Consequences in inTensive CUlture
}

\author{
Walter Reyes Avalos ${ }^{1,2}$
}

\section{Resumien}

\begin{abstract}
El estudio tuvo como objetivo describir los estados del síndrome de la ecdisis incompleta en machos adultos del camarón Cryphiops caementarius del río Pativilca (Lima, Perú), así como sus consecuencias en cultivo intensivo. Se trabajó con 54 camarones adultos que presentaban apéndices cefalotorácicos completos. El estado de muda fue observado dos veces por semana y en aquellos próximos a la ecdisis se observaron todos los días sin ser manipulados. Los resultados de las observaciones permitieron clasificar el síndrome de la ecdisis (E) incompleta en cinco subestados: $\mathrm{E}_{1}$ : Cuerpo y apéndices atrapados con su exuvia, que condujo a la muerte del camarón. $\mathrm{E}_{2}$ : Cefalotórax y apéndices cefalotorácicos atrapados con su exuvia, que condujo a la muerte del camarón. $\mathrm{E}_{3}$ : Periópodos atrapados con su exuvia, que condujo a la muerte del camarón. $\mathrm{E}_{4}$ : Ambos quelípodos atrapados con su exuvia, cuya muerte o sobrevivencia del camarón dependió de la autotomización de los quelípodos. $\mathrm{E}_{5}$ : Un solo quelípodo (mayor o menor) atrapado con su exuvia, cuya muerte o sobrevivencia del camarón dependió de la autotomización del quelípodo. El síndrome de la ecdisis incompleta en el camarón afectó la supervivencia y el rendimiento.
\end{abstract}

Palabras clave: Cryphiops; síndrome por muda; supervivencia; cultivo

\section{Abstract}

The aim of the study was to describe the stages of the incomplete ecdysis syndrome in adult shrimp males Cryphiops caementarius captured in the Pativilca River (Lima, Peru), as well as to evaluate its consequences in intensive culture. Fifty-four adult shrimp

${ }^{1}$ Laboratorio de Acuicultura Ornamental, Departamento de Biología, Microbiología y Biotecnología,

Facultad de Ciencias, Universidad Nacional del Santa, Perú

${ }^{2}$ E-mail: wreyes_avalos@hotmail.com

Recibido: 3 de julio de 2017

Aceptado para publicación: 16 de noviembre de 2017 
that had complete cephalothoracic appendages were collected. The molting stages were observed twice a week and those close to the ecdysis were observed daily without being manipulated. The results of the observations allowed to classify the incomplete ecdysis syndrome (E) in five substages: $\mathrm{E}_{1}$ : Body and appendages trapped with its exuvia, which led to the death of shrimp. $\mathrm{E}_{2}$ : Cephalothorax and cephalothoracic appendages trapped with its exuvia, which led to the death of shrimp. $\mathrm{E}_{3}$ : Pereopods trapped with their exuvia, which led to the death of the shrimp. $\mathrm{E}_{4}$ : Both chelipods trapped with their exuvia, whose death or survival of the shrimp depended on the autotomization of the chelipods. $\mathrm{E}_{5}$ : A single chelipod (major or minor) trapped with its exuvia, whose death or survival of the shrimp depended on the autotomization of the chelipod. Incomplete ecdysis syndrome affected survival and yield.

Key words: Cryphiops; moult syndrome; survival; culture

\section{INTRODUCCIÓN}

El camarón Cryphiops caementarius (Molina, 1782) es una especie promisoria para cultivo comercial (Llellish et al., 2005). Se distribuye desde los ríos de Lambayeque en Perú hasta Valparaíso en Chile (Moscoso, 2012) y soporta intensa pesquería, principalmente en los ríos de Arequipa, Perú, cuya extracción fue de $1042 \mathrm{t}$ en 2015 (Wasiw y Yépez, 2015; PRODUCE, 2016).

La muda es un evento natural en todo crustáceo para continuar con el desarrollo, la reproducción y el crecimiento. La muda es un proceso cíclico que incluye los estados de posmuda (A y B), intermuda (C), premuda (D) y culmina con la ecdisis (E) (Aiken y Waddy, 1987; Reyes y Luján, 2003). La ecdisis se divide en fase pasiva y activa. En la fase pasiva, la sutura ecdisial es descalcificada, hay ingreso de agua, aumenta la presión hidrostática y se produce abultamiento de la membrana toracoabdominal. En la fase activa hay ruptura de la membrana dorsal entre el cefalotórax y el abdomen, se levanta el cefalotórax y los apéndices cefálicos, torácicos y abdominales son retirados suavemente (Aiken y Waddy, 1987). La ecdisis es una etapa de riesgo para los crustáceos porque una vez iniciada la fase activa debe ser completada o el animal muere (Phlippen et al., 2000).
En C. caementarius, la mortalidad durante la ecdisis ocurre por canibalismo, y también por la dificultad del mismo proceso (Reyes, 2012). La muerte durante la ecdisis, conocida como el síndrome de muerte por muda sucede en Orconectes virilis (Aiken, 1968, 1969), Panulirus homarus (Thomas, 1972), Homarus americanus (Browser y Rosemark, 1981). En O. virilis, Aiken (1968) subdivide a la ecdisis normal en cuatro subestados $\left(E_{1} a E_{4}\right)$ y en la ecdisis anormal en tres subestados $\left(E_{1}\right.$ a $\left.E_{3}\right)$; sin embargo, no se han caracterizado los estados del síndrome de la muerte por ecdisis en $C$. caementarius.

De acuerdo con Reverend (2000), el síndrome de muerte por muda viene a ser una estructura fenotípica que reúne las manifestaciones o fenómenos de la alteración de un sistema, sin ser característicos de una causa en particular; es decir, que puede ser producido por causas diferentes. Por consiguiente, los objetivos del estudio fueron describir los estados del síndrome de la ecdisis incompleta en machos adultos del camarón C. caementarius y evaluar sus consecuencias en un cultivo intensivo.

\section{Materiales y MéTodos}

El estudio se realizó en un cultivo intensivo desarrollado en el Laboratorio deAcuicultura Ornamental de la Universidad 
Nacional del Santa, Perú, donde se informó por primera vez la muerte masiva de camarones C. caementarius machos desde el primer mes de cultivo (Reyes, 2012).

Se recolectaron camarones machos adultos del río Pativilca $\left(10^{\circ} 66^{\prime} 85^{\prime \prime} \mathrm{S}\right.$ $77^{\circ} 68^{\prime} 06^{\prime \prime}$ W) (Barranca, Lima). La especie $C$. caementarius se reconoció con clave taxonómica (Méndez, 1981). Se seleccionaron 54 camarones machos de un lote de 96 . Los camarones tenían $5.84 \pm 0.56 \mathrm{~cm}$ de longitud total y $8.32 \pm 1.52 \mathrm{~g}$ de peso total, $\mathrm{y}$ presentaban apéndices cefalotorácicos completos. La longitud total (desde la escotadura posorbital hasta el extremo posterior del telson) se midió con regla metálica graduada $( \pm 0.5 \mathrm{~mm})$ y con los camarones posicionados ventralmente. El peso total, así como el peso de los quelípodos, se determinaron en balanza digital ADAM AQT600 $( \pm 0.1 \mathrm{~g})$. Los camarones se alimentaron con balanceado comercial formulado para camarón de mar ( $40 \%$ de proteína total). La ración diaria (08:00 y 19:00 h) fue del 6\% del peso de cada camarón.

El cultivo se realizó en nueve acuarios de vidrio $\left(0.186 \mathrm{~m}^{2}\right.$ y $\left.55 \mathrm{l}\right)$. Cada acuario tuvo un sistema de recirculación de agua tipo airwater-lift $\left(0.431 \mathrm{~min}^{-1}\right)$ con filtro biológico percolador (2.5 1). Dentro de cada acuario se instalaron seis recipientes circulares transparentes $\left(133 \mathrm{~cm}^{2}, 201 \mathrm{~cm}^{2}\right.$ y $\left.284 \mathrm{~cm}^{2}\right)$, que se dispusieron en dos grupos de tres niveles. En cada recipiente se sembró un camarón al azar, de modo que se sembraron seis camarones por acuario (32 camarones $\mathrm{m}^{-2}$ ).

El estado de muda (Reyes y Luján, 2003) se verificó dos veces por semana y aquellos próximos a la ecdisis se observaron diariamente sin ser manipulados. Los estados del síndrome de la ecdisis incompleta se describieron según Aiken $(1968,1969)$ para Orconectes virilis. Los datos se recolectaron durante cuatro meses. Las fotografías fueron tomadas con la cámara de un teléfono celular Smartphone HTC con $8 \mathrm{Mp}$.
Para determinar la calidad del agua de los acuarios se registró mensualmente oxígeno y temperatura con oxímetro digital Sension8 $\left(7.72 \pm 0.10 \mathrm{mg} \mathrm{l}^{-1}, 23.16 \pm 0.15^{\circ} \mathrm{C}\right)$, $\mathrm{pH}$ con pHmetro digital $110(7.41 \pm 0.15)$. Además, la dureza total $(212.34 \pm 10.12$

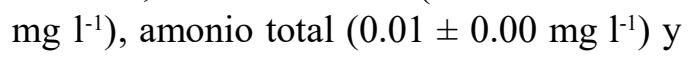
nitritos $\left(0.04 \pm 0.00 \mathrm{mg} \mathrm{l}^{-1}\right)$ fueron determinados por métodos analíticos (Fukushima et al., 1982). Los datos de muerte no asociada a la ecdisis, muerte durante la ecdisis, ecdisis con autotomía y ecdisis normal de machos se presentaron como frecuencia porcentual.

\section{Resultados}

Las ecdisis normales de C. caementarius fueron evidenciadas por el desprendimiento completo de la exuvia, sin que haya desprendimiento de apéndices ni atrapamiento de la exuvia en el cuerpo y apéndices cefalotorácicos (Figura 1).

El síndrome de la ecdisis incompleta de C. caementarius fue claramente evidenciado por observación visual, lo que permitió describir cinco subestados (Figura 2):

- $E_{l}:$ Cuerpo y apéndices atrapados con su exuvia. Todo el cuerpo del camarón estuvo ligeramente hinchado y el espacio dorsal toracoabdominal abultado. La exuvia fue difícil de ser separada del cuerpo y de los apéndices del camarón. La muerte del camarón fue inminente.

- $E_{2}$ : Cefalotórax y apéndices cefalotorácicos atrapados con su exuvia. Cefalotórax levantado hacia adelante. La exuvia de los periópodos y del abdomen aún no estuvo liberada. La exuvia fue difícil de ser separada del abdomen y de los apéndices del camarón. La muerte del camarón fue inminente.

- $E_{3}$ : Periópodos atrapados con su exuvia. Las exuvias de los periópodos aún no estuvieron liberadas. La sutura ecdisial de los periópodos se encontró ligeramente 

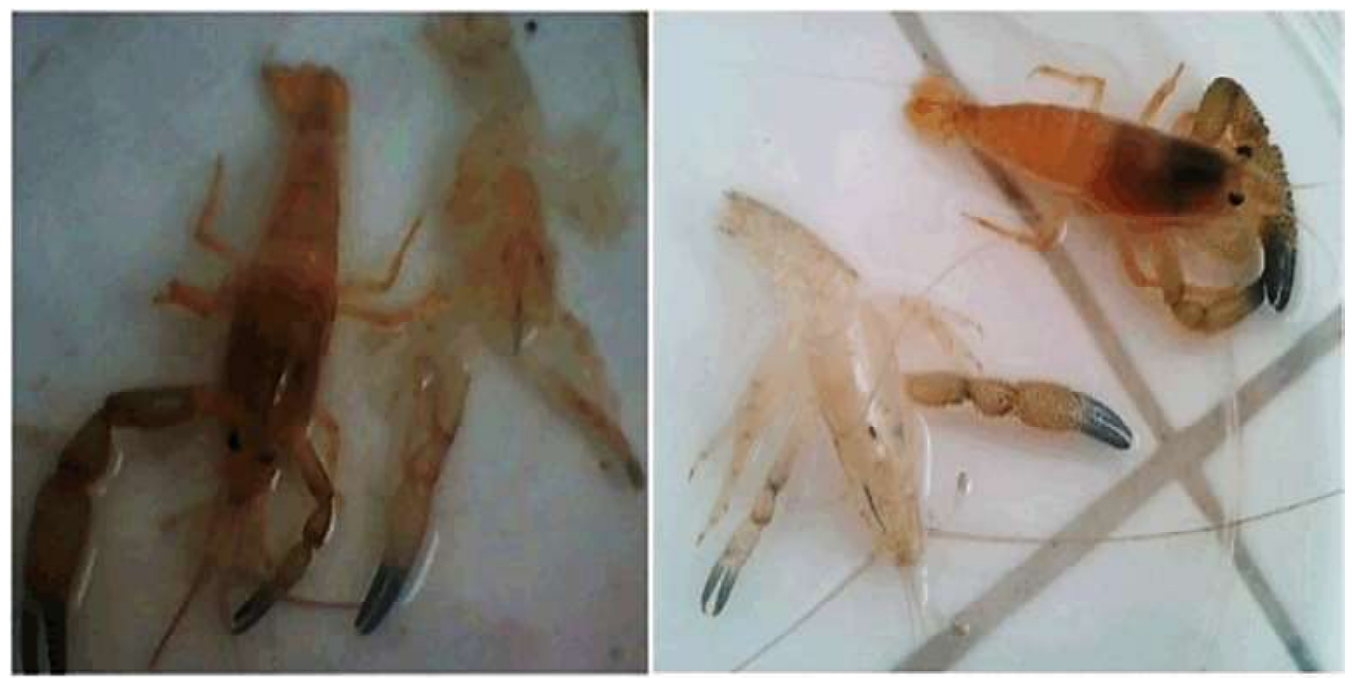

Figura 1. Ecdisis normal de C. caementarius en cultivo intensivo. Observe el exoesqueleto completo al lado de cada camarón recién mudado cuyos apéndices cefalotorácicos están completos

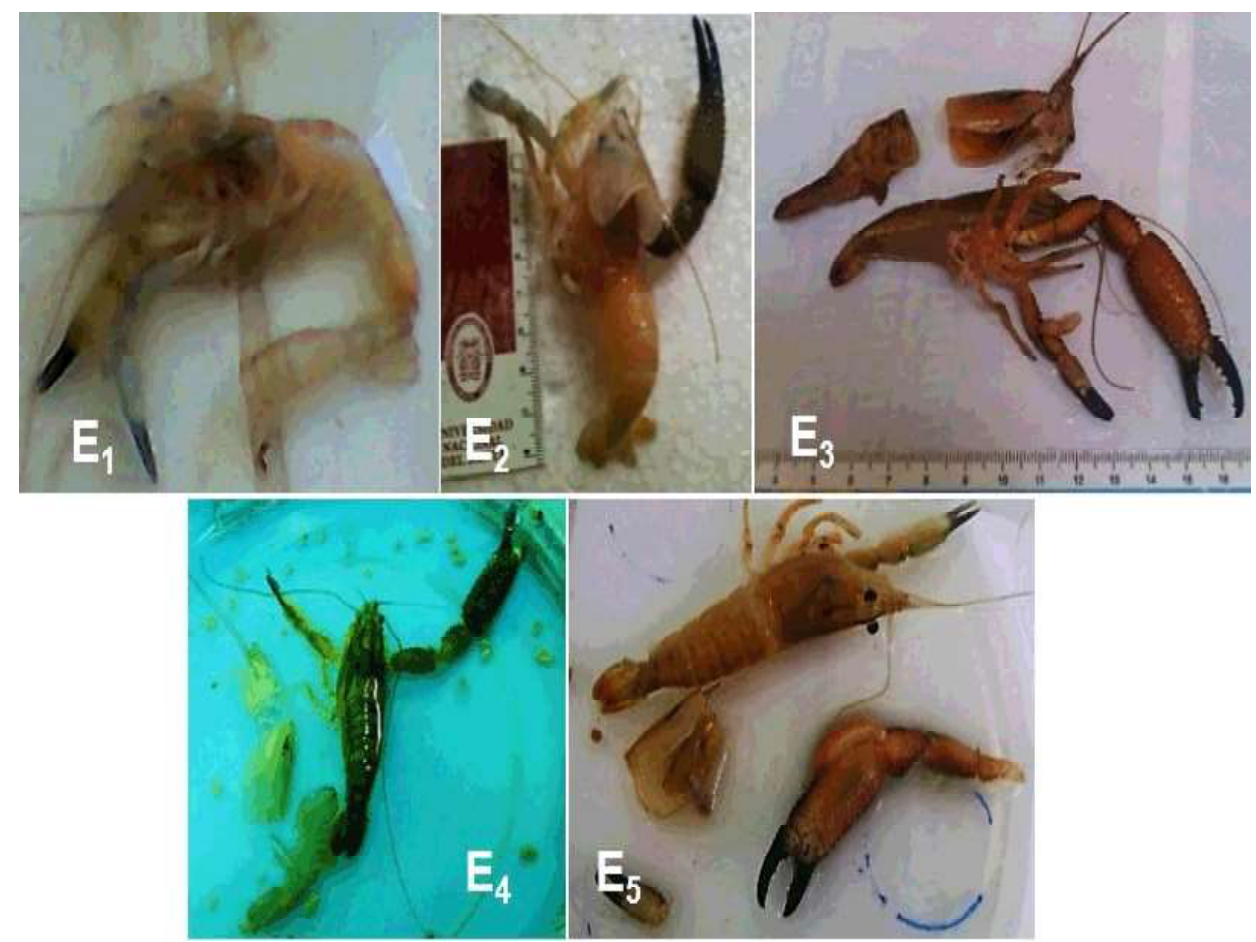

Figura 2. Subestados del síndrome de la ecdisis incompleta en machos adultos de C. caementarius en cultivo intensivo. E1: Cuerpo y apéndices atrapados con su exuvia. E2: Cefalotórax y apéndices cefalotorácicos atrapados con su exuvia. E3: Periópodos atrapados con su exuvia. E4: Ambos quelípodos atrapado con su exuvia. E5: Quelípodo mayor atrapado con su exuvia 

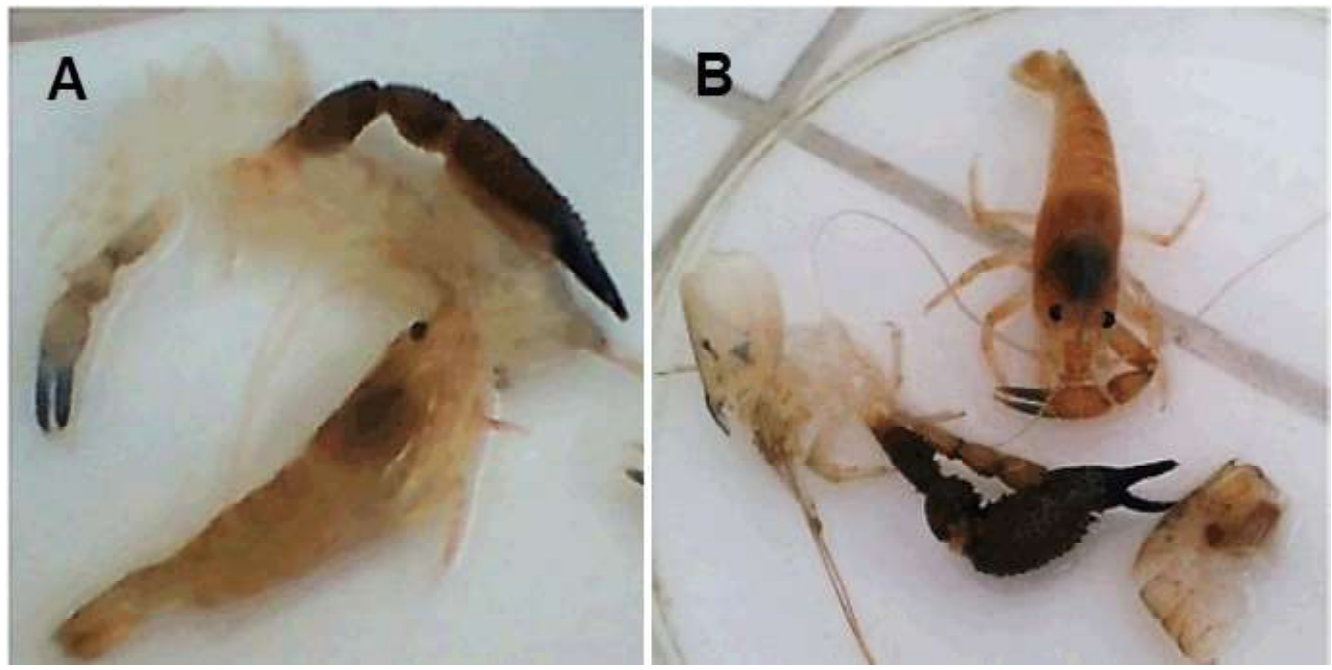

Figura 3. Autotomía de ambos quelípodos (A) y autotomía del quelípodo mayor (B) de $C$. caementarius, en cultivo intensivo

abierta en la zona de los artejos y hubo hinchamiento del músculo con el subsecuente deterioro. No fue posible separar las exuvias de los periópodos. La muerte del camarón fue inminente.

- $E_{4}:$ Ambos quelípodos atrapado con su exuvia. Las exuvias de los quelípodos mayor y menor aún no estuvieron liberadas. La sutura ecdisial de los quelípodos se encontraron ligeramente abiertas en la zona de los artejos. No fue posible separar las exuvias de los quelípodos. La sobrevivencia del camarón dependió de la autotomización de los quelípodos.

- $E_{5}$ : Quelípodo mayor atrapado con su exuvia. La exuvia del quelípodo mayor aún no estuvo liberada. La sutura ecdisial del quelípodo mayor se encontró ligeramente abierta en la zona de los artejos. No fue posible separar la exuvia del quelípodo. La sobrevivencia del camarón dependió de la autotomización del quelípodo.

En los recipientes individuales de cultivo hubo menor proporción (5\%) de muertes aisladas no asociadas a la ecdisis porque estuvieron entre los estados de muda $\mathrm{C}$ y $\mathrm{D}_{1}$.
En cambio, la proporción de muertes durante la ecdisis incompleta $\left(E_{1}, E_{2}\right.$ y $\left.E_{3}\right)$ se incrementó hasta $25 \%$ desde el segundo al cuarto mes de cultivo. De los 30 camarones sobrevivientes $(55.6 \%), 5(16.8 \%)$ realizaron ecdisis normales y $25(83.2 \%)$ sufrieron ecdisis incompleta $\left(\mathrm{E}_{4}\right.$ y $\left.\mathrm{E}_{5}\right)$ en similares proporciones (Figura 3). La pérdida del quelípodo mayor del camarón redujo el peso entre $12 \mathrm{y}$ $22 \%$ y la pérdida de ambos quelípodos entre el 30 y $40 \%$ de su peso. La regeneración de quelípodos se produjo en $22.0 \pm 1.8$ días en la muda posautotomía.

El rendimiento promedio en el sistema de cultivo intensivo después que los camarones sufrieron el síndrome de ecdisis incompleta fue de $0.3 \mathrm{~kg} \mathrm{~m}^{-2}$.

\section{Discusión}

En el cultivo intensivo de camarones machos de $C$. caementarius en crianza individual, las muertes no asociadas a la ecdisis $\left(\mathrm{C}\right.$ y $\left.\mathrm{D}_{1}\right)$ fueron menores $(5 \%)$, y podrían ser consecuencia de las condiciones de captura 
y transporte, así como por manipulación durante los muestreos, pues la mortalidad solo se evidenció en el primer mes de cultivo. Similares muertes no asociadas a la ecdisis suceden en P. homarus (Thomas, 1972) y también en $C$. caementarius (Acosta y Quiñones, 2016).

La descripción de los tres primeros subestados de la ecdisis incompleta $\left(\mathrm{E}_{1}, \mathrm{E}_{2} \mathrm{y}\right.$ $\mathrm{E}_{3}$ ) de C. caementarius fue similar a lo descrito por Aiken (1968) en O. virilis. Sin embargo, se informa dos subestados adicionales $\left(\mathrm{E}_{4} \mathrm{y}_{5}\right)$ en $C$. caementarius, en los cuales los individuos tuvieron posibilidades de sobrevivir.

El síndrome de la ecdisis incompleta en machos de C. caementarius apareció desde el segundo mes de cultivo, donde los camarones que murieron se encontraron en los subestados $E_{1}, E_{2}$ y $E_{3}$ de la ecdisis. Similares consecuencias en estos subestados suceden en O. virilis (Aiken, 1968), P. homarus (Thomas, 1972) y H. americanus (Browser y Rosemark, 1981). De acuerdo con Phlippen et al. (2000), una vez que se inicia la fase activa de la ecdisis debe completarse o el crustáceo muere.

Los subestados $\mathrm{E}_{4}$ y $\mathrm{E}_{5}$ se caracterizaron porque las exuvias de los quelípodos de los camarones no se liberaron, y en su intento de sobrevivir realizaron autotomía de los quelípodos. El hinchamiento del tejido muscular en las suturas ecdisiales de los quelípodos habría estimulado la autotomía de los quelípodos (Mariappam y Balasundaram, 1999; Reyes et al., 2017).

La reducción entre 12 y $40 \%$ del peso del camarón por autotomía de los quelípodos se encuentra dentro del rango informado para la especie (Reyes, 2016; Reyes et al., 2017). Sin embargo, los camarones que realizaron autotomía de quelípodos $\left(\mathrm{E}_{4} \mathrm{y} \mathrm{E}_{5}\right)$ tuvieron una muda precoz que permitió en corto tiempo (22 días) regenerar las piezas perdidas, tiempo similar al reportado para la especie (Reyes et al., 2017). No obstante, los quelípodos regenerados en la siguiente muda no fueron del mismo tamaño que los iniciales, lo que afectó la producción. Esta reducción del tamaño de lo quelípodos se debe a que el proceso de regeneración necesita de energía metabólica adicional a las requeridas para las funciones de desarrollo y reproducción (Maginnis, 2006).

La aparición del síndrome de la ecdisis incompleta redujo el rendimiento $\left(0.3 \mathrm{~kg} \mathrm{~m}^{-2}\right)$ en comparación con el rendimiento proyectado (1.0 kg m${ }^{-2}$, Reyes, 2016) en cultivo intensivo en recipientes individuales.

\section{Conclusiones}

El síndrome de la ecdisis incompleta en machos adultos de C. caementarius presentó cinco subestados diferenciables y afectó la supervivencia y el rendimiento del camarón en cultivo intensivo.

\section{Agradecimientos}

A los estudiantes Mónica BernabéAlva e Iliana Zavala Zavaleta, del VIII ciclo de la Escuela de Biología en Acuicultura de la Universidad Nacional del Santa, por el apoyo logístico recibido en la investigación.

\section{Literatura Citada}

1. Acosta AJ, Quiñones DP. 2016. Efecto de dietas con bajas concentraciones de lecitina de soya sobre el crecimiento, muda y supervivencia de machos del camarón de río Cryphiops caementarius. Tesis para Título. Perú: Univ. Nacional del Santa. 36 p.

2. Aiken DE. 1968. Subdivisions of stage E (ecdysis) in the crayfish Orconectes virilis. Can J Zool 46: 153-155. doi: 10.1139/z68-024

3. Aiken DE. 1969. Photoperiod, endocrinology and the crustacean molt cycle. Science 164: 149-155. doi: 10.1126/ science.164.3876.149 
4. Aiken DE, Waddy SL. 1987. Molting and growth in crayfish: a review. Canada: Fisheries and Environmental Sciences, Fisheries Research Branch, Department of Fisheries and Oceans, Biological Station. $34 \mathrm{p}$.

5. Browser PR, Rosemark R. 1981. Mortalities of cultured lobster, Homarus, associated with a molt death syndrome. Aquaculture 23: 11-18. doi: 10.1016/ 0044-8486(81)90003-X

6. Fukushima M, Sifuentes G, Saldaña G, Castillo G, Reyes J, Shimokawa L. 1982. Métodos limnológicos. Trujillo, Perú: Departamento de Ciencias Biológicas, Univ. Nacional de Trujillo. $119 \mathrm{p}$.

7. Leellish M, Silva I, Martínez C, Del Pozo P. 2005. Producto 4, Perú. Elaboración de criterios de cobertura geográfica para el establecimiento de áreas prioritarias para el desarrollo del biocomercio. [Internet]. Disponible: http:/ /191.98.188.189/Fulltext/11121.pdf

8. Maginnis TL. 2006. The costs of autotomy and regeneration in animals: a review and framework for future research. Behav Ecol 17: 857-887. doi: 10.1093/beheco/ar1010

9. Mariappan P, Balasundaram $C$. 1999. Molt-related limb loss in Macrobrachium nobilii. Current Sci 77: 637639.

10. Méndez M. 1981. Claves de identificación y distribución de los langostinos y camarones (Crustacea: Decapoda) del mar y ríos de la costa del Perú. Bol IMARPE 5: 1-170.

11. Moscoso V. 2012. Catálogo de crustáceos decápodos y estomatópodos del Perú. Bol IMARPE 27: 1-209.

12. Phlippen MK, Webster SG, Chung JS, Dircksen H. 2000. Ecdysis of decapod crustaceans is associated with a dramatic release of crustacean cardioac- tive peptide into the haemolymph. J Exp Biol 203: 521-536.

13. [PRODUCE] Ministerio de la Producción. 2016. Anuario estadístico pesquero y acuícola. Perú: Ministerio de la Producción. [Internet]. Disponible en: http://www.produce.gob.pe/documentos/ estadisticas/anuarios/anuario-estadisticopesca-2015.pdf

14. Reverend H. 2000. Una reflexión sobre el concepto de síndrome. Rev Fac Med Colombia 48: 241-242.

15. Reyes WE, Lujan H. 2003. Estados y subestados del ciclo de muda del camarón de río (Cryphiops caementarius Molina, 1872) (Crustacea: Decapoda: Palaemonidae). CIVA 2003: 808-817.

16. Reyes WE. 2012. Crecimiento y la supervivencia de hembras y machos del camarón de río C. caementarius criados en sistema de recipientes individuales de diferentes tamaños con recirculación de agua. Tesis Doctoral. Perú: Universidad Nacional de Trujillo. $89 \mathrm{p}$.

17. Reyes W. 2016. Effect of culture container on the survival and growth of male Cryphiops caementarius in individualized systems. Rev Bio Ciencias 3: 311325. doi: 10.15741/revbio.03.04.06

18. Reyes W, Terrones S, Baltodano I. 2017. Effects chelipeds regeneration in molting and growth of male Cryphiops caementarius Molina 1782 (Decapod, Palaemonidae). Rev Bio Ciencias 4: 118. doi: 10.15741/revbio.04.04.05

19. Thomas MM. 1972. Growth of the spiny lobster, Panulirus homarus (Linnaeus), in captivity. Indian J Fish 19(1-2): 125-129.

20. Wasiw J, Yépez V. 2015. Evaluación poblacional del camarón Cryphiops caementarius en ríos de la costa sur del Perú. Rev Inv Vet Perú 26: 166-181. doi: 10.15381/rivep.v26i2.11103 